\title{
Acute respiratory distress in Maniitsoq, Greenland
}

\author{
Patricia Duch ${ }^{1 *}$, Niels E Ebbehøj ${ }^{2}$, Folmer Lynggaard ${ }^{1}$ \\ From 4th Danish Emergency Medicine Conference \\ Roskilde, Denmark. 25-26 November 2011
}

\section{Background}

Inhalation of aerosols of surface active substances is a known risk factor for development of acute respiratory distress syndrome (ARDS). A number of small case series are reported with exposure for aerosols from spraycans with textile or leather protecting agents. We report a series of cases with respiratory symptoms in a group of 39 persons exposed to a floor-sealing product, Anti Fleck Super(R) (AFS).

Case: In 2010, a supermarket in the Greenlandic town Maniitsoq, was under renovation.

A $300 \mathrm{~m} 2$ floor was sprayed with AFS. The spraying created a fog of aerosols of poly-fluorinated silicones. Craftsmen, employees, and customers inhaled the aerosols during a period of minutes to 3 hours. Within hours 39 persons developed cough, dyspnoea and fever in varying degrees.

It was necessary to evacuate the 39 patients with progressive symptoms, by airplane from the small hospital in Maniitsoq, to the well-equipped Dronning Ingrids Hospital (DIH), Nuuk. Triage was used.

\section{Methods}

Symptoms were recorded in Maniitsoq and DIH. All patients had arterial blood analyses and chest x-rays taken on arrival to DIH. Two months after the incident, the patients were offered a thoroughly clinical follow-up with lung function test, oxygen-saturation working test and chest $\mathrm{x}$-ray.

The patients: male and female, mean age 33 years, mainly without earlier medical record. Almost all were smokers.

\section{Results}

Within few hours 39 persons developed symptoms of respiratory distress.

\footnotetext{
* Correspondence: pduch@hotmail.com

'Dept. of Internal Medicine Dronning Ingrids Hospital, Nuuk, Greenland

Full list of author information is available at the end of the article
}

Mainly difficulty breathing, coughing, flu-like symptoms, tachycardia, fever and reduced oxygen saturation level. Seven patients had acute lesions on chest X-ray.

All symptoms peaked and virtually subsided within 24 hours. Except in 3 patients, hospitalized in intensive care, who had severe respiratory symptoms for 48 hours, Sat. average $80 \%$. At clinical follow-up, 15 patients still experienced difficulty breathing during hard physical work. But all had normal medical examinations including normal saturation during exercise.

\section{Conclusion}

The Greenlandic healthcare system has a set-up that makes it capable of managing acute situations even up to a larger scale. Evacuation and the management in the hospitals functioned optimally throughout the acute situation.

Poly-fluorinated silicones are potent chemicals able to produce pulmonary toxicity even at low-intensive exposure levels.

Author details

${ }^{1}$ Dept. of Internal Medicine Dronning Ingrids Hospital, Nuuk, Greenland.

${ }^{2}$ Dept. of Occupational Medicine, Bispebjerg University Hospital, Denmark.

Published: 16 April 2012

doi:10.1186/1757-7241-20-S2-O1

Cite this article as: Duch et al:: Acute respiratory distress in Maniitsoq, Greenland. Scandinavian Journal of Trauma, Resuscitation and Emergency Medicine 2012 20(Suppl 2):01. 